\section{LA-UR-03-0749}

Approved for public release;

distribution is unlimited.

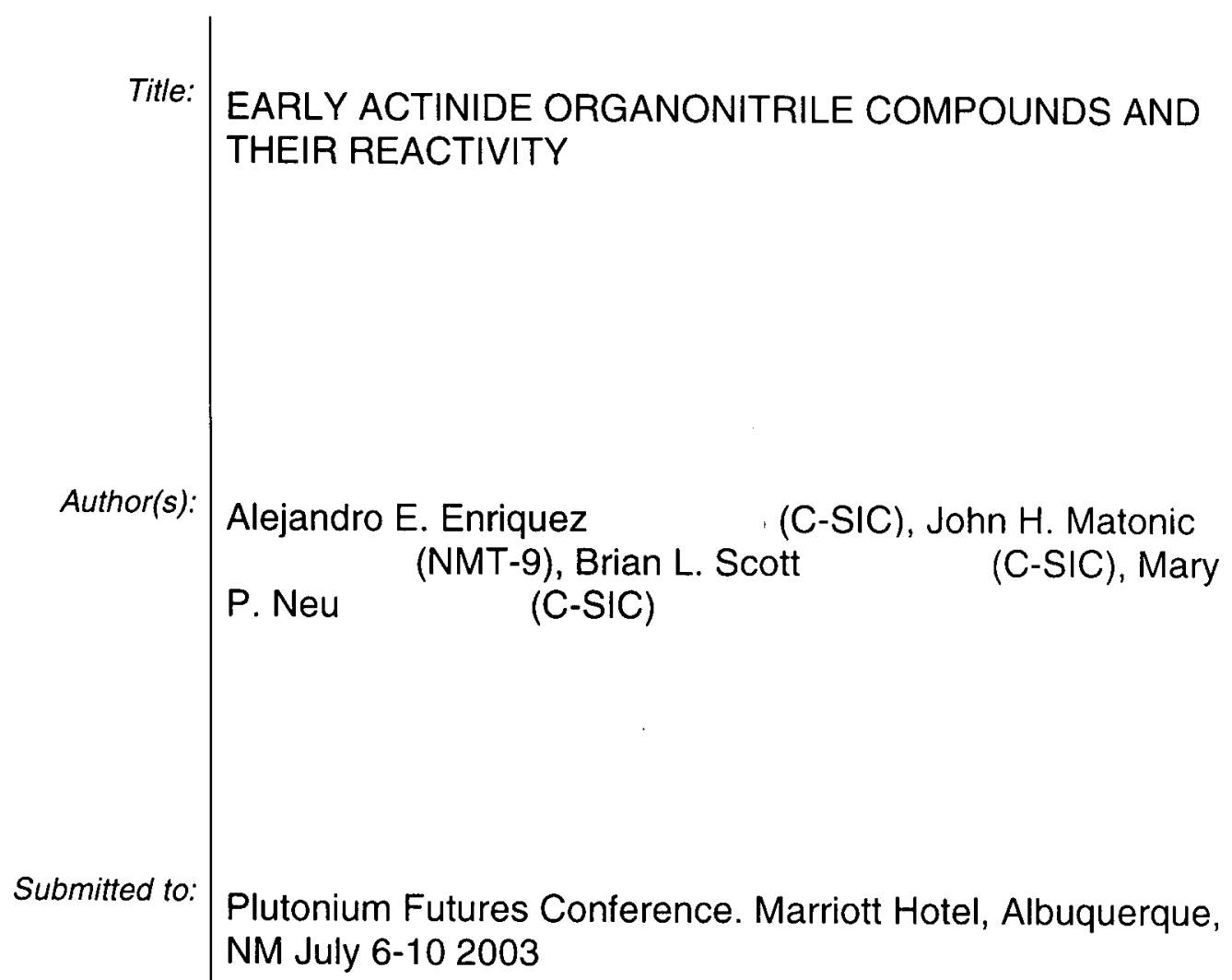

NM July 6-10 2003

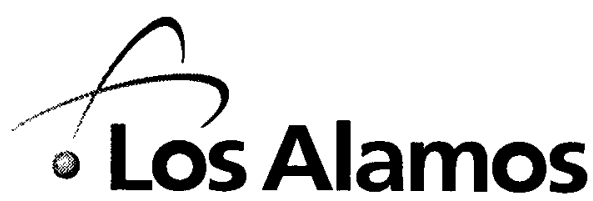

NATIONAL LABORATORY

Los Alamos National Laboratory, an affirmative action/equal opportunity employer, is operated by the University of California for the U.S. Department of Energy under contract W-7405-ENG-36. By acceptance of this article, the publisher recognizes that the U.S. Government retains a nonexclusive, royalty-free license to publish or reproduce the published form of this contribution, or to allow others to do so, for U.S. Government purposes. Los Alamos National Laboratory requests that the publisher identify this article as work performed underthy auspices of the U.S. Department of Energy. Los Alamos National Laboratory strongly supports academic freedom and a resea $\equiv$ publish; as an institution, however, the Laboratory does not endorse the viewpoint of a publication or guarantee its technical cors.ness. 


\title{
Early actinide organonitrile compounds and their reactivity
}

\author{
Alejandro E. Enriquez, John H. Matonic, Brian L. Scott, and Mary P. Neu*
}

Actinide, Catalysis, and Separations Chemistry (C-SIC), Chemistry Division Los Alamos National Laboratory, Los Alamos, New Mexico, 87545, USA. Fax: (505) 667-9905; Tel: (505)667-7717; E-mail: mneu@lanl.gov

\section{Introduction}

The actinide trihalides are an important class of materials. Anhydrous $\mathrm{AnX}_{3}$ compounds have been prepared via high temperature synthetic techniques, but they exist as polymeric solids, which are insoluble in organic solvents. ${ }^{1-3}$ Transuranic complexes $\mathrm{AnI}_{3}(\mathrm{THF})_{\mathrm{x}}$ have been prepared by the reaction of metals with $\mathrm{C}_{2} \mathrm{H}_{4} \mathrm{I}_{2}$ in THF solutions $(\mathrm{An}=\mathrm{Pu}, \mathrm{x}=5 ; \mathrm{An}=\mathrm{Np}, \mathrm{x}=4)^{4}$ and can be viewed as a net oxidation of An metal with 1.5 equivalents molecular iodine. A convenient preparation of organic solvent soluble trivalent actinide compounds has been described where 1.5 equivalents of $\mathrm{I}_{2}$ are added to actinide $(\mathrm{An})$ metal turnings $(\mathrm{An}=\mathrm{Pu}, \mathrm{U}, \mathrm{Np})$ suspended in aprotic organic coordinating

solvent. ${ }^{5,6}$ Since virtually all nonaqueous An(III) complexes have been prepared through the triodide-tetrahydrofuran complex, we are interested in preparing complexes with solvents other than tetrahydrofuran. And, since uranium is often used as a surrogate for studying the chemistry of transuranic actinides, we are seeking to elucidate the chemical differences between the transuranic elements and uranium. In this presentation we . describe new $\mathrm{Pu}(\mathrm{III})$ complexes prepared by plutonium metal oxidation with either iodine 
or metal hexafluorophosphate salts in acetonitrile. We also revisit the oxidation of uranium metal by iodine in acetonitrile. ${ }^{7.9}$ Finally, we also describe a new, versatile, mononuclear $\mathrm{U}(\mathrm{IV})$ product, $\mathrm{UL}_{4}(\mathrm{NCPh})_{4}$, obtained from the oxidation of uranium metal by iodine in benzonitrile.

\section{Results}

Treatment of plutonium metal suspended in acetonitrile by iodine generated a blue solution. We attribute the blue color to in-situ generation of $\mathrm{PuI}_{3}(\mathrm{NCMe})_{\mathrm{x}}(\mathbf{1})$. Although we have been unable to characterize 1 , addition of a single equivalent of the $f$ element extractant tpza $\left(\right.$ tpza $=$ tris[2-pyrazinyl) methyl]amine $\left.=\mathrm{N}\left(\mathrm{CH}_{2}\left(\mathrm{C}_{4} \mathrm{H}_{3} \mathrm{~N}_{2}\right)\right)_{3}\right)$ to the blue solution resulted in isolation of the $\mathrm{Pu}(\mathrm{III})$ derivative, (tpza) $\mathrm{PuI}_{3}(\mathrm{NCMe})$ (2). Green crystals of $\mathbf{2}$ were characterized by x-ray crystallography.

Oxidation of excess uranium metal with 1.5 equivalents of iodine in acetonitrile has been reported to provide $\mathrm{UI}_{3}(\mathrm{NCMe})_{4}(3)^{7}$. We were able to isolate a single crystal from this reaction after the solution was cooled to $-38^{\circ} \mathrm{C}$. X-ray crystallography identified this product as the mixed valence $\mathrm{U}(\mathrm{IV}) / \mathrm{U}(\mathrm{III})$ compound $\left[\mathrm{UI}_{6}\right]\left[\mathrm{U}(\mathrm{NCMe})_{9}\right][\mathrm{I}]$ (4). The cationic portion of the molecule is a homoleptic U(III) ion surrounded by nine acetonitrile molecules. This nine-coordinate cation is flanked by a non-coordinating iodide and the $\mathrm{U}(\mathrm{IV})$ dianionion $\mathrm{UI}_{6}{ }^{2-}$. When the oxidation of uranium metal was carried out in benzonitrile, the mononuclear $\mathrm{U}(\mathrm{IV})$ product $\mathrm{UI}_{4}(\mathrm{NCPh})_{4}(\mathbf{5})$ is obtained in $\sim 80 \%$ yield. 


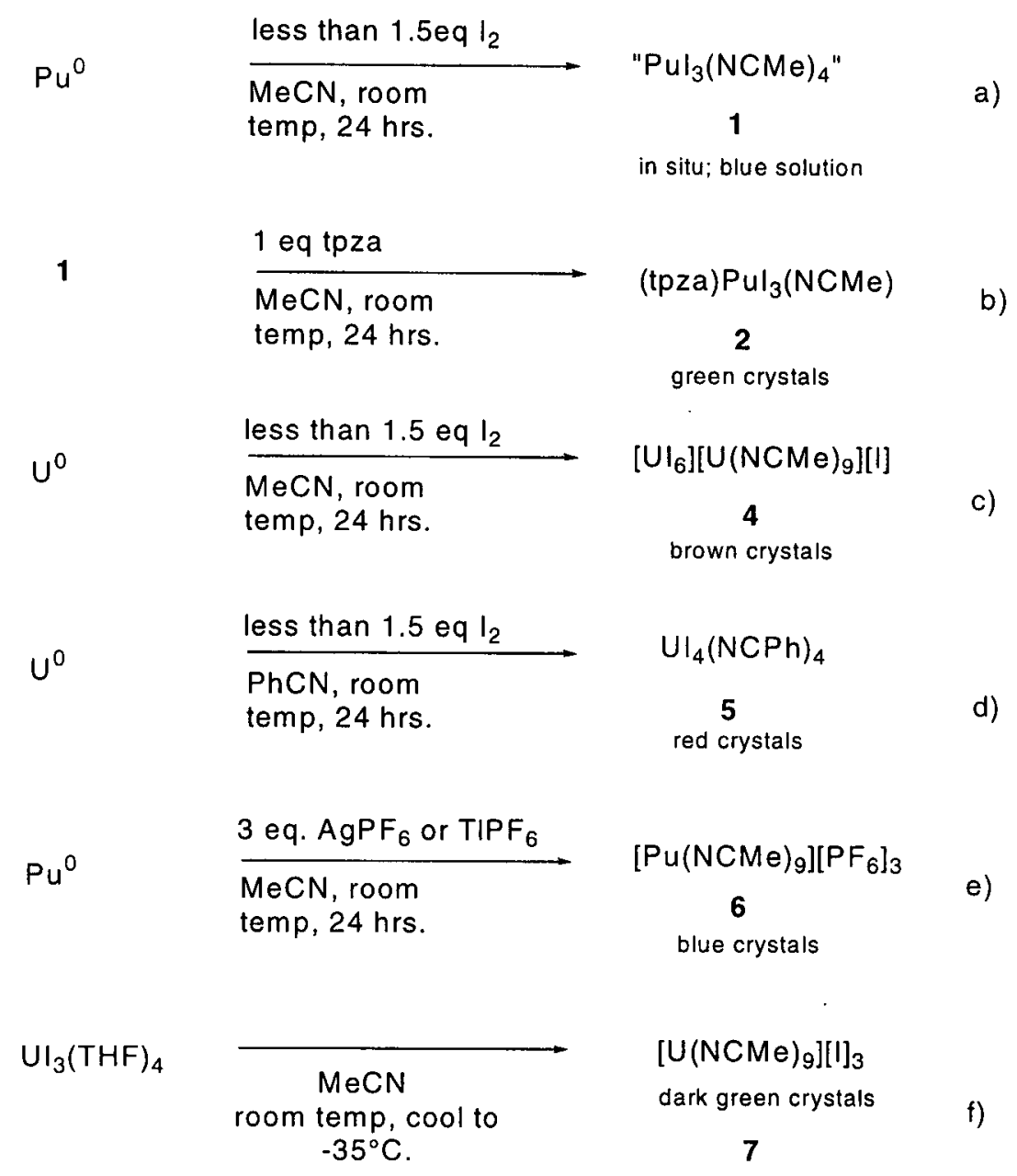

Figure 1. Preparation of $\mathrm{Pu}$ (III), U (III) and U(IV) nitrile complexes.

Addition of three equivalents of either $\mathrm{AgPF}_{6}$ or $\mathrm{TIPF}_{6}$ to an acetonitrile suspension of ${ }^{239} \mathrm{Pu}$ metal gradually provided a blue solution as plutonium metal dissolved and either silver or thallium metal precipitated. Filtration of the solution followed by slow evaporation of acetonitrile formed blue crystalline $\left[\mathrm{Pu}(\mathrm{NCMe})_{9}\right]\left[\mathrm{PF}_{6}\right]_{3} \cdot \mathrm{MeCN}(6)$ in $\sim 80 \%$ yield. Attempts to prepare the nine-coordinate homoleptic acetonitrile uranium analogue of $\mathbf{6}$ by treatment of uranium turnings suspended in acetonitrile with either $\mathrm{AgPF}_{6}$ or $\mathrm{TlPF}_{6}$ were unsuccessful. No reaction was 
observed even after days of stirring. However, dissolution of blue $\mathrm{UI}_{3}(\mathrm{thf})_{4}$ in acetonitrile resulted in a dark green solution which, upon cooling to $-38^{\circ} \mathrm{C}$, provided dark-green crystals of the nine-coordinate $\mathrm{U}(\mathrm{III})$ acetonitrile salt $\left[\mathrm{U}(\mathrm{NCMe})_{9}\right]\left[\mathrm{I}_{3}(\mathbf{6})\right.$. Crystals of $\mathbf{6}$, unlike the plutonium analogue 5 , are thermally unstable and rapidly decompose at room temperature to an undetermined black residue.

\section{Discussion}

The uranium and plutonium nitrile compounds isolated from $\mathrm{An}^{0}$ oxidation reactions in polar aprotic solvents are consistent with known differences between the reactivities of uranium and plutonium metal. For example, plutonium oxidation by iodine in either thf or pyridine solutions gives well characterized $\mathrm{PuI}_{3}(\text { sol })_{4}$ products (these $\mathrm{Pu}(\mathrm{III})$ have been characterized by TGA, ${ }^{1} \mathrm{H}$ NMR, IR and UV/vis/near-IR spectroscopies). Our efforts to isolate and structurally characterize $\mathbf{1}$, the intermediate prepared by oxidation of $\mathrm{Pu}^{0}$ with iodine in $\mathrm{MeCN}$, have been unsuccessful. However, 1 is clearly $\mathrm{Pu}(\mathrm{III})$ because it can be trapped by tpza to form the $\mathrm{Pu}(\mathrm{III})$ compound 2 . Plutonium metal also undergoes a unique reaction in acetonitrile when it is treated with silver and thallium hexafluorophosphate salts to provide the homoleptic $\mathrm{Pu}(\mathrm{III})$ acetonitrile salt 6 . We have not yet prepared a Pu(IV) compound by direct oxidation of $\mathrm{Pu}^{0}$ in polar aprotic solvents.

Unlike plutonium, uranium metal can be oxidized by iodine in polar aproic solvents to provide both $\mathrm{U}(\mathrm{III})$ and $\mathrm{U}(\mathrm{IV})$ products. When excess metal is present, $\mathrm{U}^{0}$ oxidation by 1.5 equivalents of iodine in thf, pyridine, or dme solvents gives the well characterized $\mathrm{U}(\mathrm{III})$ products $\mathrm{UI}_{3}(\mathrm{sol})_{\mathrm{x}}$ (thf and py, $\mathrm{x}=4$; dme, $\mathrm{x}=2$ ) (although $\mathrm{UI}_{3}\left(\right.$ thf $_{4}$ is the only one to be structually characterized). Preparation of $\mathrm{UI}_{3}(\mathrm{NCMe})_{4}$ in an 
analogous fashion has been reported. Our attempts to prepare this complex by direct oxidation of $\mathrm{U}^{0}$ with iodine in acetonitrile gave the dark brown crystalline mixed valence $\mathrm{U}(\mathrm{IV}) / \mathrm{U}(\mathrm{III})$ salt 4 . Curiously, oxidation of excess uranium metal in benzonitrile with iodine cleanly provides crystalline $\mathbf{5}$ in high yield. No evi dence for a $\mathrm{U}(\mathrm{III})$ product is observed. Complex $\mathbf{5}$ is soluble and stable in toluene, benzene, and methylene chloride for days. However, when $\mathbf{5}$ is dissolved in acetonitrile a reaction occurs. The crystalline material isolated from the reaction is a brown product characterized by $\mathrm{x}$-ray crystallography as $\left[\mathrm{UI}_{6}\right]\left[\mathrm{U}(\mathrm{NCMe})_{7} \mathrm{I}_{2}\right]$. We are currently examining the reactivity of 5 towards neutral and anionic chelating ligands.

\section{References}

(1) Katz, J. J.; Seaborg, G. T.; Morss, L. R.; Editors The Chemistry of the Actinide Elements, Vol.1 and 2. 2nd Ed, 1986.

(2) Levy, J. H.; Taylor, J. C.; Wilson, P. W. Acta Crystallogr., Sect. B: Struct. Crystallogr. Cryst. Chem. 1975, B31, 880-882.

(3) Taylor, J. C.; Wilson, P. W. Acta Crystallogr., Sect. B: Struct. Crystallogr. Cryst. Chem. 1974, B30, 2803-2805.

(4) Karraker, D. G. Inorg. Chim. Acta 1987, 139, 189-191.

(5) Avens, L. R.; Bott, S. G.; Clark, D. L.; Sattelberger, A. P.; Watkin, J. G.; Zwick, B. D. Inorg. Chem. 1994, 33, 2248-2256.

(6) Clark, D. L.; Sattelberger, A. P. Inorg. Synth. 1997, 31, 307-315.

(7) Drozdzynski, J.; du Preez, J. G. H. Inorg. Chim. Acta 1994, 218, 203-205. 
(8) Du Preez, J. G. H.; Zeelie, B. J. Chem. Soc. Chem. Comm. 1986, 743.

(9) Du Preez, J. G. H.; Zeelie, B. Inorg. Chim. Acta 1986, 118, L25-L26. 